\title{
CONSTRUÇÃO E APLICAÇÃO DE ELETRODO DE AÇO INOXIDÁVEL UNS S31254 COMO ELETRODO INDICADOR EM TITULAÇÕES CONDUTIMÉTRICAS
}

\author{
Lúcia Helena Terra, Nivaldo Torres e Silvia Maria Leite Agostinho
}

Instituto de Química, Universidade de São Paulo, Av. Prof. Lineu Prestes, 748, 05508-900 São Paulo - SP

Recebido em 16/10/01; aceito em 29/5/02

\begin{abstract}
CONSTRUCTION AND APPLICATION OF UNS S31254 STAINLESS STEEL AS INDICATOR ELECTRODE IN CONDUCTIMETRIC TRITATIONS. UNS S31254 SS electrodes have been built to substitute platinum in conductimetric titrations. The electrodes were tested in both acid-basic titration (chloridric acid and sodium hydroxide) and precipitation titration (sodium chloride and argentum nitrate as titrant). The practical application was exemplified from conductimetric tritations of $\mathrm{HF}_{-} \mathrm{HNO}_{3}$ mixtures used in metalurgical industry to passivate stainless steels. The results were compared with those obtained using commercial platinum electrodes. The equivalent volumes obtained were comparable within $3 \%$ experimental error. Its application depends on the nature of electrolyte. These results have shown that stainless steel, less expensive than platinum (about three order of magnitude), can substitute platinum electrodes in routine analyses and didactic laboratories.
\end{abstract}

Keywords: UNS S31254 stainless steel; indicator electrode; conductimetric titration.

\section{INTRODUÇÃO}

Tem crescido, nos últimos anos, o número de investigações científicas em que se procura substituir metais inertes como ouro e platina, por ligas metálicas, em particular aços inoxidáveis, em aplicações eletroanalíticas. No Brasil, estudos têm sido realizados por diferentes grupos de pesquisadores; Flach et al. ${ }^{1}$ mostraram, por potenciometria, o emprego do aço inoxidável EF 138 na padronização de ácidos fracos por bases fortes. Santos et $a l^{2}{ }^{2}$ estudaram o mesmo aço como eletrodo indicador potenciométrico de ácido fosfórico em refrigerantes. Chissini, Jacobsen, Viaro e Adaime ${ }^{3}$ mostraram a viabilidade do emprego do aço UNS S31603 como substituinte da platina em titulações potenciométricas do íon Fe (II) por dicromato de potássio em meio de ácido sulfúrico. Fatibello Filho et $a l .{ }^{4}$ estudaram o emprego de eletrodos de óxido de antimônio, de estanho, de tungstênio, de titânio, de aço inoxidável 316 L (UNS S31603) em titulações de ácidos graxos e etanolaminas. Zampronio e colaboradores ${ }^{5}$ mostraram que o aço inoxidável 316 pode ser utilizado como eletrodo indicador em titulações potenciométricas, quando se utiliza análise por injeção em fluxo. Por outro lado, Nomura e Ujihira $^{6}$ mostraram que óxidos formados sobre a superfície de aços inoxidáveis 304 e 316 tornam viável a utilização destes materiais como medidores de $\mathrm{pH}$. Estes aços apresentam comportamento nernstiano em $\mathrm{pH}$ variando desde 1 até 13 , mesmo em soluções contendo íons de metais alcalinos, amônio, sulfato, e nitrato. Na presença de íons cloreto, o aço 304 não se comporta como eletrodo indicador para íons $\mathrm{H}^{+}$, o mesmo não acontecendo com o aço 316, que não se mostrou afetado pela presença de íons cloreto. Nomura e Ujihira ${ }^{6}$ explicam este fato pelo maior teor, no aço 316 , de Mo; o óxido deste metal seria o responsável pela estabilidade deste aço.

Lowy e OniCiu ${ }^{7}$ também mostraram que o aço 316 pode ser utilizado como eletrodo indicador em titulação potenciométrica ácido base. Medido contra um eletrodo de calomelano saturado, este material age como um sensor de $\mathrm{pH}$. A titulação ácido - base de $\mathrm{HCl}$ com $\mathrm{NaOH}$ reproduz a típica curva em "S" da titulação. O eletrodo de aço

*e-mail: smlagost@iq.usp.br também responde linearmente à variação de pH entre 2 e 12; este comportamento se deve ao recobrimento deste material com um filme de óxido. Gomes e colaboradores ${ }^{8}$ também demostraram a viabilidade do emprego do aço 316 em titulações potenciométricas de L - Arginina em solvente não aquoso (ácido acético glacial), após tratamento superficial prévio, pela imersão deste material em solução de $\mathrm{CrO}_{3}$.

O aço inoxidável especial tipo 254 apresenta em sua composição elevados teores de $\mathrm{Cr}(20 \%)$, Ni (18\%) e Mo (6\%) e foi especialmente desenvolvido com o intuito de resistir a diversos meios agressivos, em especial meios contendo íons cloreto. Tem sido mostrado que este material possui uma maior resistência à corrosão em água do mar, quando comparado a outros materiais, como por exemplo o aço 316 L. Comparado ao aço 304, o aço 254 também apresenta uma maior resistência à corrosão sob tensão em meio de cloreto de sódio9. Em meio de ácido clorídrico, este material apresenta corrosão generalizada somente em condições severas de temperatura e concentração. De Micheli ${ }^{9}$ mostrou que o aço inoxidável especial UNS S31254 pode ser utilizado como eletrodo indicador em titulações potenciométricas em sistemas onde o aço se encontre passivo, mas o seu desempenho depende da natureza do eletrólito suporte e da natureza do par redox envolvido (no caso de titulações de óxido-redução). Estudos potenciométricos mostraram que o par ferri ferrocianeto em meios de cloreto, para $\mathrm{pH}$ variando entre 0 e 6,5, responde bem à equação de Nernst, quando se emprega o referido aço com valor do coeficiente angular próximo ao teoricamente esperado $(59 \mathrm{mV})$. Estudos voltamétricos da interfase aço $254 /\left[\mathrm{Fe}(\mathrm{CN})_{6}\right]^{-3}$, $\left[\mathrm{Fe}(\mathrm{CN})_{6}\right]^{-2}, \mathrm{KCl}$ 1,0 mol L-1 mostraram que o par redox apresenta comportamento irreversível, mas as densidades de corrente de pico catódica e anódica mostram-se proporcionais à concentração de $\left[\mathrm{Fe}(\mathrm{CN})_{6}\right]^{-3}$ na solução, mostrando que, para análises quantitativas este material pode ser satisfatoriamente empregado ${ }^{10}$.

Os aços 254 e F138 foram também utilizados em medidas de condutividade com o objetivo de se determinar o valor da constante de equilíbrio de ionização (Ka) para o ácido acético ${ }^{11}$. Estes estudos mostraram que os valores de Ka encontrados, quando se utilizam quaisquer um dos dois materiais, foram comparáveis aos obtidos quando se utiliza eletrodo de platina, bem como ao valor encontrado na literatura. 
Embora existam na literatura trabalhos que tratam do emprego de aços inoxidáveis como eletrodos indicadores, estes se referem a medidas potenciométricas. Neste trabalho, serão mostradas aplicações deste material metálico em titulações condutimétricas.

\section{OBJETIVOS}

Este trabalho tem como objetivos: construir um eletrodo de aço inoxidável UNS S31254 (aço 254) visando a sua aplicação, em substituição à platina, em medidas de condutividade; caracterizar o eletrodo para este fim, a partir de titulações convencionais ácido - base e de precipitação; mostrar a viabilidade do emprego deste eletrodo em titulações condutimétricas visando aplicação tecnológica; comparar os resultados obtidos com este material e com eletrodo de platina.

\section{PARTE EXPERIMENTAL}

\section{Construção do eletrodo}

O eletrodo de aço 254 foi construído na forma de disco de $5 \mathrm{~mm}$ de diâmetro e $1 \mathrm{~mm}$ de espessura e embutido, pela face externa, na resina "polylite T - $208 \mathrm{R}$ ", que corresponde ao poli (ftalato - maleato de propileno) estirenizado ${ }^{12}$, tendo-se o cuidado de deixar uma das faces do disco exposta à solução. O eletrodo, através de um furo, foi ligado a um fio de cobre para contato elétrico, tendo a sua extremidade desencapada também embutida na resina. A Figura 1 mostra o eletrodo indicador de aço utilizado.

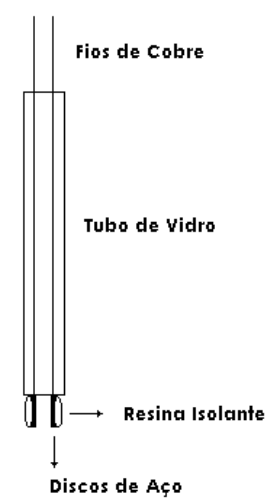

Figura 1. Eletrodo de aço inoxidável 254 utilizado em titulações condutimétricas

O eletrodo de platina utilizado nestes ensaios foi o eletrodo de condutividade comercial, da marca Digimed.

\section{Soluções}

Para as titulações ácido - base foram utilizadas soluções de $\mathrm{HCl}$ com concentração aproximada de $0,01 \mathrm{~mol} \mathrm{~L}^{-1}$ e como titulante solução de $\mathrm{NaOH}$ com concentração igual a $0,0088 \mathrm{~mol} \mathrm{~L}^{-1}$, padronizada com ftalato ácido de potássio; nas titulações de precipitação utilizaram-se soluções de $\mathrm{NaCl}$ com concentração aproximada de $0,1 \mathrm{~mol} \mathrm{~L}^{-1}$ e $\mathrm{AgNO}_{3}$ com concentração igual a $0,100 \mathrm{~mol} \mathrm{~L}^{-1}$. Para as titulações que envolveram sistemas de interesse industrial foram utilizadas soluções de banhos de decapagem ácida industrial (mistura $\mathrm{HF}+\mathrm{HNO}_{3}$ com porcentagens em volume iguais a 5 e $20 \%$, respectivamente), que foram diluídas até a concentração aproximada de $0,01 \mathrm{~mol} \mathrm{~L}^{-1} \mathrm{e}$, como titulante, a mesma solução de hidróxido anteriormente descrita. Todas as soluções foram preparadas utilizando-se reagentes de grau analítico e água deionizada.

\section{Limpeza dos eletrodos}

Os eletrodos de platina foram previamente lavados em água morna $\left(50{ }^{\circ} \mathrm{C}\right)$ por aproximadamente $10 \mathrm{~min}$ e posteriormente em solução de $\mathrm{H}_{2} \mathrm{SO}_{4} 0,5 \mathrm{~mol} \mathrm{~L}^{-1}$, por $1 \mathrm{~min}$; os eletrodos de aço 254 foram lixados com lixa de granulometria 600 e lavados com água deionizada.

\section{Temperatura de trabalho}

As titulações foram realizadas à temperatura de $25^{\circ} \mathrm{C}$, utilizando-se um termostato da marca Quimis, modelo 215 D1 BS.

\section{Equipamento}

Foi utilizado um condutivímetro da marca Metrohm Herisau, modelo E 382 .

Antes de se realizarem as titulações condutimétricas determinou-se a constante de célula para cada um dos diferentes eletrodos utilizados. Para isto utilizou-se uma solução padrão de $\mathrm{KCl}$, com concentração igual a $0,0200 \mathrm{~mol} \mathrm{~L}^{-1}$, cuja condutividade ( $\left.\kappa\right)$ é bem conhecida ${ }^{13}$ e igual a $0,002786 \mathrm{~S} \mathrm{~cm}^{-1}$.

Através da relação

$\kappa=\mathrm{k}_{\mathrm{cel}} / \mathrm{R}$

onde: $\kappa=$ condutividade da solução; $\mathrm{k}_{\text {cel }}=$ constante de célula; $\mathrm{R}=$ resistência medida, foi possível determinar as constantes de célula $\left(\mathrm{k}_{\text {cel }}\right)$ para cada um dos eletrodos.

Através das medidas de resistência da solução após a adição de alíquotas do titulante, e com as respectivas constantes de célula de cada um dos eletrodos, determinaram-se as condutividades das soluções obtidas.

O volume equivalente em cada uma das titulações foi determinado pela extrapolação da parte linear das curvas, antes e após o ponto final da titulação.

\section{RESULTADOS E DISCUSSÃO}

Este trabalho aborda diferentes aspectos da utilização de aço inoxidável como eletrodo indicador em titulações condutimétricas. Um primeiro aspecto consiste na utilização do aço inoxidável 254 como eletrodo indicador em titulações ácido - base e em reações de precipitação que são sistemas bem conhecidos. Posteriormente, foram realizadas titulações condutimétricas em sistemas que envolvem aplicação industrial: determinação da acidez total de uma mistura fluor - nítrica, empregada em banho de decapagem - passivação na indústria metalúrgica.

\section{Titulações envolvendo reações ácido - base}

As Figuras 2 e 3 mostram as curvas de titulação de $\mathrm{HCl}$ por $\mathrm{NaOH}$ utilizando-se os diferentes eletrodos indicadores. A partir destas curvas pode-se determinar o volume equivalente para cada titulação efetuada.

A Tabela 1 mostra os valores de concentração de $\mathrm{HCl}$ encontrados, dependendo do eletrodo utilizado, a partir dos valores de volumes equivalentes determinados através das Figuras 2 e 3 .

A Tabela 1 mostra que os valores de concentração encontrados para cada uma das diferentes soluções são os mesmos, dentro da precisão experimental de 1\%, independente do tipo de eletrodo utilizado. Quando se analisam as curvas 2 e 3, porém, vê-se que ocorrem diferenças nos valores absolutos de condutividade, quando os eletrodos indicadores são comparados. Os valores para o aço 254 são sempre maiores que os obtidos para a platina. Estes resultados sugerem a presença de íons metálicos na vizinhança dos eletrodos de aço, como resultado de um pequeno processo de oxidação do material ferroso. 


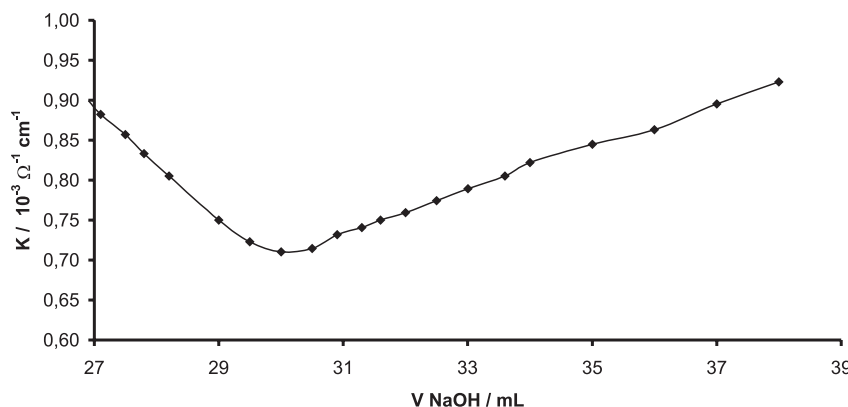

Figura 2. Titulação condutimétrica do $\mathrm{HCl}$ por $\mathrm{NaOH}$, utilizando-se eletrodo de platina como eletrodo indicador

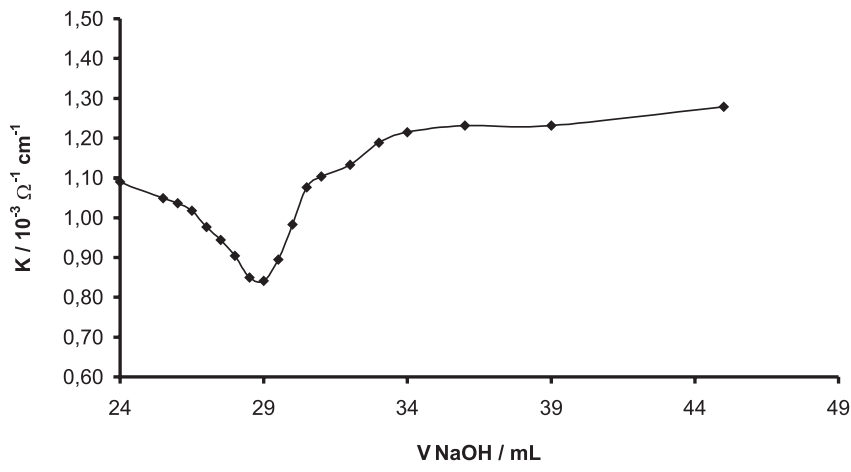

Figura 3. Titulação condutimétrica do $\mathrm{HCl}$ por $\mathrm{NaOH}$, utilizando-se eletrodo de aço 254 como eletrodo indicador

Tabela 1. Concentrações de $\mathrm{HCl}$ obtidas através de titulações condutimétricas utilizando-se diferentes eletrodos indicadores

\begin{tabular}{ccc}
\hline Soluções & Eletrodo de Pt & Eletrodo de aço 254 \\
\hline $\mathrm{HCl}$ & $0,0104 \pm 0,0001$ & $0,0101 \pm 0,0001$ \\
\hline
\end{tabular}

\section{Titulação envolvendo reações de precipitação}

As Figuras 4 e 5 mostram as curvas de titulação condutimétrica para a titulação de $\mathrm{NaCl}$ por $\mathrm{AgNO}_{3}$. Os valores de concentração de $\mathrm{NaCl}$ obtidos a partir das titulações são mostradas na Tabela 2.

Novamente se observa que os valores de concentração obtidos nos dois casos (eletrodo de platina e eletrodo de aço 254) estão coincidentes, dentro da precisão experimental, muito embora os valores de condutividade não o sejam. Quando se observam as curvas referentes à titulação de $\mathrm{NaCl}$, percebe-se que, tanto antes quanto após o ponto de equivalência, existem comportamentos distintos quando se utiliza o eletrodo de platina e o eletrodo de aço 254 . Neste caso, a pequena oxidação do aço em meio de cloreto de sódio deve formar cloro - complexos de ferro, cromo e níquel, que atenuam a mudança de condutividade antes do ponto de equivalência. Por este motivo, a derivada após o ponto de equivalência torna-se relativamente maior no caso do aço, diferente do observado com o eletrodo de platina.

\section{Titulação condutimétrica de banhos de decapagem ácida industrial}

O banho de decapagem ácida industrial utilizado neste trabalho consiste de uma mistura de ácidos nítrico e fluorídrico, com porcentagens em volume iguais a 20 e $5 \%$, respectivamente. Antes de se

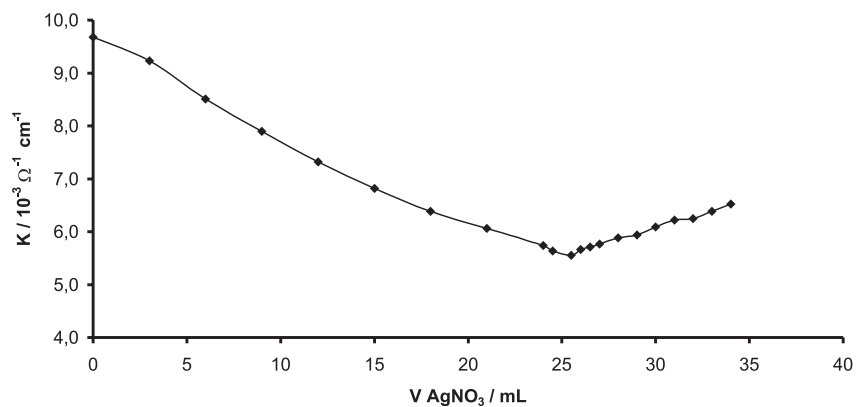

Figura 4. Titulação condutimétrica do $\mathrm{NaCl}$ por $\mathrm{AgNO}_{3}$, utilizando-se eletrodo de platina como eletrodo indicador

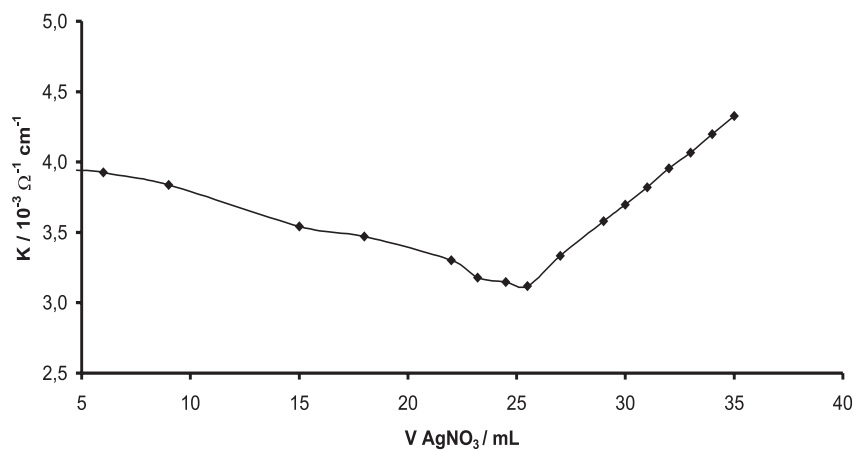

Figura 5. Titulação condutimétrica do $\mathrm{NaCl}$ por $\mathrm{AgNO}$, utilizando-se eletrodo de aço 254 como eletrodo indicador

Tabela 2. Concentrações de $\mathrm{NaCl}$ obtidas através de titulações condutimétricas utilizando-se diferentes eletrodos indicadores

\begin{tabular}{ccc}
\hline Soluções & Eletrodo de Pt & Eletrodo de aço 254 \\
\hline $\mathrm{NaCl}$ & $0,101 \pm 0,001$ & $0,104 \pm 0,003$ \\
\hline
\end{tabular}

realizarem as titulações, as soluções foram diluídas para uma concentração aproximada de $0,01 \mathrm{~mol} \mathrm{~L}^{-1}$.

As Figuras 6 e 7 mostram as curvas de titulação obtidas quando se utilizam os diferentes eletrodos. Pode-se verificar que os eletrodos de platina e de aço 254 apresentam volumes equivalentes comparáveis. Neste caso, os valores numéricos de condutividade, ao longo da titulação, são também comparáveis para a platina e o aço 254. Com efeito, a mistura fluornítrica, por ser passivante, torna a oxidação do aço praticamente imensurável. A partir do ponto de equivalência a condutividade cresce pouco, em virtude da precipitação dos íons metálicos presentes no banho de decapagem.

A Tabela 3 mostra os valores do teor ácido na mistura ácida utilizada em decapagem.

Os valores observados na Tabela 3 demonstram que o aço 254 se mostrou eficiente na determinação da concentração, quando se comparam os valores obtidos para este material com aqueles encontrados quando se utiliza eletrodo de platina.

\section{CONCLUSÕES}

Os resultados obtidos neste trabalho permitem tirar as seguintes conclusões: o aço 254 substitui a platina em titulações condutimétricas de ácido clorídrico por hidróxido de sódio, dentro de um erro experimental de $1 \%$; o aço 254 substitui a platina em titulações conduti- 


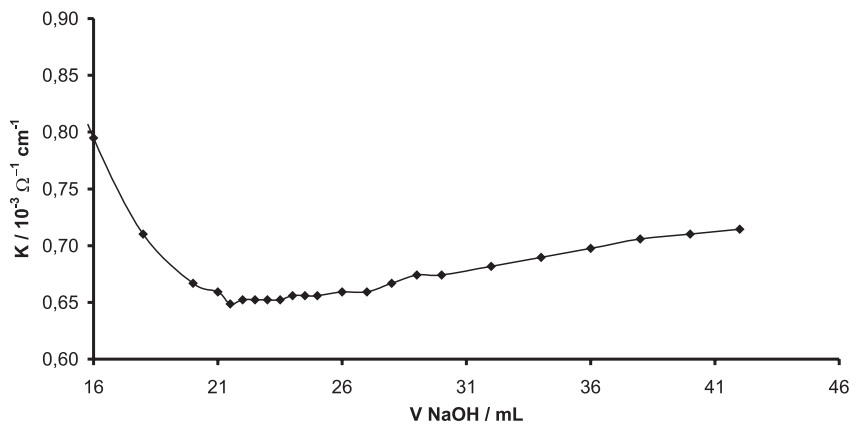

Figura 6. Titulação condutimétrica de banhos de decapagem ácida industrial por $\mathrm{NaOH}$, utilizando-se eletrodo de platina como eletrodo indicador

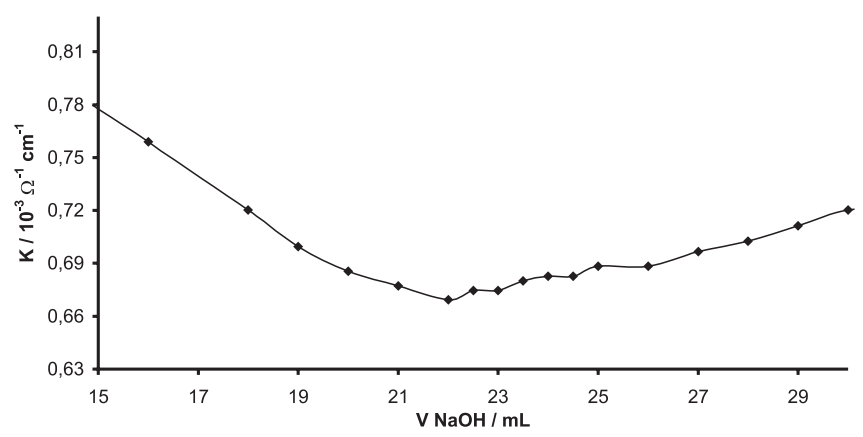

Figura 7. Titulação condutimétrica de banhos de decapagem ácida industrial por $\mathrm{NaOH}$, utilizando-se eletrodo de aço 254 como eletrodo indicador

Tabela 3. Concentrações do banho de decapagem ácida obtidas através de titulações condutimétricas utilizando-se diferentes eletrodos indicadores

\begin{tabular}{ccc}
\hline Soluções & Eletrodo de Pt & Eletrodo de aço 254 \\
\hline Banho de decapagem & $0,0075 \pm 0,0001$ & $0,0077 \pm 0,0002$ \\
\hline
\end{tabular}

métricas de cloreto de sódio por nitrato de prata, dentro de um erro experimental de 3\%; o aço 254 pode ser utilizado na determinação condutimétrica de acidez total de banhos de decapagem - passivação $\mathrm{HF}(5 \%)-\mathrm{HNO}_{3}(20 \%)$; devido ao baixo custo comparado à platina, o aço 254 é recomendável tanto na análise industrial de rotina quanto em laboratórios didáticos.

\section{AGRADECIMENTOS}

Ao engenheiro A. Sokolovski, da empresa Villares Metals, pelo fornecimento das soluções de banhos de decapagem ácida industrial. Ao CNPq, pela bolsa concedida à L. H. Terra.

\section{REFERÊNCIAS}

1. Flach, A.; Adaime, M. B.; Viaro, N. S. S.; VIII Encontro Nacional de Química Analítica, Belo Horizonte, Brasil, 1995.

2. Santos, E. P.; Naue, J.A.; Adaime, M. B.; Viaro, N. S. S.; Resumos da $19^{a}$ Reunião Anual da Sociedade Brasileira de Química, Poços de Caldas, Brasil, 1996.

3. Chissini, D.V.; Jacobse, J. R.; Viaro, N. S. S.; Adaime, M. B; Resumos da $16^{a}$ Reunião Anual da Sociedade Brasileira de Química, Caxambu, Brasil, 1993.

4. Fatibello Filho, O.; Neves, E. F. A.; Carvalho, W. M.; Capelato, M. D.; Bulhões, L. O. S.; IV Simpósio Brasileiro de Eletroquímica e Eletroanalítica, São Carlos, Brasil, 1984.

5. Zampronio, C. G.; Rohwedder, J. J. R.; Poppi, R. J.; Talanta 2000, 51, 1163.

6. Nomura, K.; Ujihira, Y.; Anal. Chem. 1988, 60, 2564.

7. Lowu, D. A.; OniCiu, L.; Analyst 1996, 121, 363.

8. Gomes, F. G.; Saavedra, J. J. P.; Vargas, S. M.; Revista da Sociedad Química de México 1997, 41, 3.

9. De Micheli, L.; Tese de Doutoramento, Universidade de São Paulo, Brasil, 1998.

10. Clemente, C. F. M. Z.; Tada, E. B.; Sousa, I. V.; Agostinho, S. M. L.; Anais do XXXIX Congresso Brasileiro de Química, Goiânia, Brasil, 1999.

11. Sampaio, A. C.; Terra, L. H.; Torres, N.; Agostinho, S. M. L.; Resumos da $24^{a}$ Reunião Anual da Sociedade Brasileira de Química, Poços de Caldas, Brasil, 2001.

12. Mano, E. B.; Polímeros como Materiais de Engenharia, Edgard Blucher Ed. Ltda, 1991.

13. Chemical Rubber Company; Handbook of Chemistry and Physics, CRC Press Inc., 74" ed., Flórida, EUA, 1993 - 1994. 